\title{
Difficult Laparoscopic Cholecystectomy
}

\author{
Jurij Janež* \\ Department of Abdominal Surgery, University Medical Centre Ljubljana, Slovenia, Europe
}

Received: November 07, 2017; Published: December 12, 2017

*Corresponding author: Jurij Janež, Department of Abdominal Surgery, University Medical Centre Ljubljana, Zaloška Cesta 7, 1525 Ljubljana, Slovenia, Europe, Tel: +386 51315 815; Email: jurij.janez@gmail.com

\section{Mini Review}

Laparoscopic cholecystectomy (LC) has dramatically replaced conventional open cholecystectomy [1]. LC was introduced by Mouret in 1987. It is one of the most common procedures being performed by the general surgeons all over the world. With more and more endeavors being made in the field of laparoscopy, more and more complicated cases, which were relatively contraindicated a few years ago, are now being performed laparoscopically. Advantages of LC are a better cosmesis, shorter hospital stay, shorter recovery time and decreased morbidity [2]. Nowadays LC has become the gold standard not only for routine gall bladder removal due to asymptomatic or symptomatic gall stones but also for the treatment of acute gall bladder inflammation [3]. One of the most important aspects of safe LC is a meticulous dissection of the structures in the triangle of Calot. Cystic duct and cystic artery must be recognised and carefully dissected to prevent intraoperative injury of major bile duct and right hepatic artery or excessive intraoperative bleeding. Rate of conversion from laparoscopic to open technique can be minimized by adhering to the basic principles of surgery and keeping in mind the critical anatomy while doing the safe and meticulous dissection [4]. In certain circumstances difficult LC can be expected. Difficult LC can be anticipated based on the pre-operative and intra-operative factors such as old age, male sex, history of multiple attacks of gall stones or repeated admissions, diabetes mellitus, previous upper abdominal surgery, liver cirrhosis and patients presenting with acute cholecystitis, pancreatitis or cholangitis [1-4].

Difficult LC is considered in cases of dense adhesions at the triangle of Calot, contracted and fibrotic gall bladder, previous upper abdominal surgery, acutely inflammed and gangrenous gall bladder, empyema of the gall bladder, Mirizzi's syndrome, previous cholecystostomy and cholecystogastric or cholecystoduodenal fistula [4,5]. Every case should be considered as difficult until completed successfully. Level of difficulty may vary with the skill and experience of the surgeon but conditions, mentioned above, are really difficult, irrespective of the experience and skill of the surgeon. Bile duct injury is the most catastrophic event that can happen to the patient during LC, leaving the patient with high morbidity and high treatment cost. Measures taken to prevent bile duct injury are careful dissection of the triangle of Calot, keeping in mind the anatomy of the hepatobiliary system and possible an anatomic variations and step-by-step progression until removal of the gall bladder [6]. In cases of unclear anatomy and failure to progress in laparoscopic dissection, conversion to the open procedure should be done and it should not be taken as a failure or a complication on the part of the surgeon $[6,7]$.

\section{Conclusion}

Difficult LC can be expected in certain circumstances. Some scoring and validation systems have been recommended to predict difficult cases. Step-by-step meticulous dissection of the triangle of Calot should be performed to avoid bile duct injury. Conversion to open procedure should be done in cases of unclear anatomy or failure to progress in laparoscopic dissection.

\section{References}

1. Hussain A (2011) Difficult laparoscopic cholecystectomy: current evidence and strategies of management. Surg Laparosc Endosc Percutan Tech 21(4): 211-217.

2. Lal P, Agarwal PN, Kumar Malik V, Chakravarti AL (2002) A Difficult Laparoscopic Cholecystectomy That Requires Conversion to Open Procedure Can Be Predicted by Preoperative Ultrasonography. JSLS 6: 59-63.

3. Murthy Vivek MAK, Augustine AJ, Rao R (2014) A comprehensive predictives coring method for difficult laparoscopic cholecystectomy. J Minim Access Surg 10(2): 62-67.

4. Gupta N, Ranjan G, Arora MP, Goswami B, Chaudhary P, et al. (2013) Validation of a scoring system to predict difficult laparoscopic cholecystectomy. International Journal of Surgery 11(9): 1002-1006.

5. Sugrue M, Sahebally SM, Ansaloni L, Zielinski MD (2015) Grading operative findings at laparoscopic cholecystectomy- a new scoring system. World Journal of Emergency Surgery 10:14.

6. Singh K, Ohri A (2005) Laparoscopic cholecystectomy - is there a need to convert? J Minim Access Surg 1(2): 59-62.

7. Selmani R, Karagjozov A, Stefanovska V (2013) Conversions in laparoscopic cholecystectomy in acute versus chronic cholecystitis. Pril (Makedon Akad Nauk Umet Odd Med Nauki) 34(2): 43-50. 


$\begin{array}{ll}\text { BIOMEDICAL } & \text { Assets of Publishing with us } \\ \text { - GeSERCHES } & \text { Global archiving of articles }\end{array}$

